\title{
Citalopram and Tianeptine: Pharmacological Interventions in alcohol withdrawal-syndrome and serotonin insufficiency in Albino Wistar male rats
}

\author{
Iffat Ara ${ }^{1,2 *}$ and Samina Bano ${ }^{1}$
}

1. Clinical Biochemistry and Psychopharmacology Research Unit, Department of Biochemistry, University of Karachi, Karachi-75270, Pakistan

2. Faculty of Allied Health Sciences, School of Medical Lab Technology, Minhaj University, 365-M, Model Town, Lahore, Pakistan

Info Article
Submitted: $19-02-2019$
Revised: $19-03-2019$
Accepted: $19-04-2019$
*Corresponding author
Iffat Ara
Email:
iffatarak@hotmail.com

\section{ABSTRACT}

The present study aims to investigate the neurochemical and behavioral effects of alcohol withdrawal (AW) syndrome in rats. Serotonergic antidepressants such as Citalopram and tianeptine at a dose of $20 \mathrm{mg} / \mathrm{kg}$ were tested separately for their ability to prevent seizures in AW groups of rats. Brain regional tryptophan (TRP), 5-hydroxytryptamine (5-HT; serotonin), 5-hydroxyindoleacetic acid (5-HIAA) concentrations were determined using high-performance liquid chromatography connected to the fluorimetric detector. Data analyzed showed increases brain TRP concentrations in all the three regions (amygdala, hippocampus and hypothalamus) after citalopram administered alcohol withdrawn rats; however, tianeptine increases brain TRP concentrations only in amygdala and hippocampus. Increases in brain serotonin concentrations were seen in all the regions only in citalopram administered alcohol withdrawn rats. Further, tianeptine was shown to increase 5-HT turnover in all the regions, however, citalopram appeared to increase 5-HT turnover only in the hippocampus. It is concluded that the citalopram and tianeptine behave differently on the intrinsic pathway of serotonin metabolism that appeared to be compensated by the pattern of 5-HT release. Further, it could be inferred that exposure of serotonergic agents might restore serotonin reuptake mechanism that is desensitized following chronic alcohol exposure. Thus the inclusive approach of the serotonergic system plays an undoubted role in the pharmacological management of AW syndrome.

Keywords: Serotonin, antidepressants, tryptophan, tianeptine, citalopram

\section{INTRODUCTION}

Alcohol withdrawal syndrome characterized by a set of symptoms such as tremor, anxiety, restlessness, insomnia that begins as early as $6 \mathrm{~h}$ after the initial decline from peak intoxication and the seizures may occur in untreated patients in acute alcohol withdrawal. Many alcoholdependent patients also experience psychologic problems, such as depression, anxiety, and impulsivity related to serotonin dysfunction (Pihl and Le Marquand, 1998; Thompson, 1978). Interestingly In alcohol withdrawn rats behavioral signs such as audiogenic seizures, locomotor hyperactivity, agitation, and wet dog shakes and tremors have been reported. (Hunter et al., 1975; Uzbay, 2008; Oretti, 1996).

Behavioral deficit during alcohol withdrawal syndrome in rats (Majchrowicz, 1975; Uzbay and Kayaalp, 1995) constitutes the involvement of both neuroendocrine and serotonergic system. Behavioral adaptation during alcohol dependence involves the activation of corticotrophin releasing hormone (CRH) system (Sarnyai et al., 2001) in the hypothalamus that projects to the serotonergic system in limbic brain areas such as hippocampus and amygdala (Koob, 2000; Oscar- Berman, 2000).

Recently, neuroimaging technology has made scientists enable to report shrinkage of total 
brain size (Banerjee, 2014; Zahr and Pfefferbaum, 2017;; Harper et al., 2005). and changes in brain structures (Rosenbloom and Pfefferbaum, 2008). These brain areas are cerebral cortex and subcortical areas such as the limbic system that supports feeling of emotions include amygdala, the thalamus (signals communication within the brain), the hypothalamus (releases hormones in response to stressful stimulus and is important for behavioral physiological functions) and the hippocampus that constitutes learning and memory functions (OscarBerman, 2000).

Tianeptine a selective serotonin reuptake enhancer (SSRE) is a modified tricyclic antidepressant that has been shown to be therapeutically active in patients of depression with a history of alcohol dependence (Hindmarch, 2001; Favre et al., 1997). Studies on stereochemistry in drug action revealed that $l$ isomer is therapeutically more active form than $d$ isomers of tianeptine and its neuroprotective effects become more challenging on 5-HT- mediated behavioral deficits that alter stress-induced morphological changes (Oluyomi et al., 1997; Brink et al., 2006; Liu et al., 2011). However, contradictory evidence proves it as a drug of abuse and addiction because of its structural similarity with antidepressant amphetamine. The existing uncertain profile of tianeptine regarding its safety suggests its coadministration with hypnotics could be useful (Vadachkoria et al., 2009; Calabozo et al., 2016).

Citalopram is a selective serotonin reuptake inhibitor (SSRI), comprises 1:1 ratio of escitalopram and R- citalopram (Sanchez, 2006). Escitalopram has a 50 fold higher affinity for the human serotonin reuptake transporter compared to R-citalopram (Senchez, 2006; Zhong et al., 2009).

Previously, we have reported that citalopram and tianeptine $(10 \mathrm{mg} / \mathrm{kg})$ improve serotonin dysfunction by enhancing free tryptophan uptake from periphery to the brain (Bano et al., 2010; Ara and Bano, 2012).This paper argues the comparative mechanism of action of tianeptine $20 \mathrm{mg} / \mathrm{kg} / \mathrm{ml}$ ) and citalopram $(20 \mathrm{mg} / \mathrm{kg} / \mathrm{ml})$ with reference to brain regional tryptophan and serotonin levels in alcohol withdrawn rats.

\section{MATERIAL AND METHODS}

\section{Animals and treatment}

All animal procedures described below were conducted in strict accordance with the national research council for the care and use of laboratory animals (1996). Ethical approval was obtained from the institutional animal ethics committee, University of Karachi. All efforts were made to minimize the number of animals and any pain/distress they might incur. Locally bred male Albino Wistar rats weighing 200-250g were housed in a quiet temperature $\left(22 \pm 3^{\circ} \mathrm{C}\right)$ and humiditycontrolled room maintained on which $12 \mathrm{~h}$ dark: light cycle.

\section{Chronic ethanol administration to rats}

Eight animals/ group were assigned for controls (Matched controls) and other groups (alcohol treated and alcohol withdrawal). Rats for the behavioural study were different from those used for neurochemical estimation The rats were housed in quiet room and were given alcohol-free liquid diet ad libitum for three days before introducing alcohol into the diet alcohol was administered in modified liquid diet as described earlier (Ara and Bano, 2015). Alcohol was then added to the liquid diet in the proportion of $8 \%$ $(\mathrm{V} / \mathrm{V})$. Matched control rats were fed isocaloric amounts of the alcohol-free liquid diet, in which the alcohol contribution was substituted with maltosedextrin. Treatment of rats was continued for 28 days and the weight of the rats was recorded daily. Other relevant experimental details have already been described in detail earlier (Bano et al., 1996).

\section{Measurement of blood alcohol concentration}

Blood alcohol concentrations were determined by alcohol dehydrogenase (EC 1.1.1.1) based enzymatic procedure (Badawy and Aliya, 1984). in rats given a chronic treatment of ethanol liquid diet. The blood ethanol concentration was determined in rats (not- withdrawn, $0 \mathrm{~h}$ ) in $\mathrm{mg} / \mathrm{dL}$ $306 \pm 43$, was calculated as means \pm SEM of eight rats.

\section{Assessment of the alcohol withdrawal behaviour}

For the assessment of the effects of alcohol withdrawal signs, the alcohol containing liquid diet was substituted with drinking water for $7 \mathrm{~h}$ (before the rats were killed by this time signs of withdrawal were strongest. At each observation time, rats were assessed simultaneously for behavioral signs including agitation, tremors, stereotyped behaviors and wet dog shakes (Hunter et al., 1975). An experiment was also designed for studying the prevention of alcohol withdrawal induced disturbances in brain tryptophan metabolism. 
In the experiment both control and test animals were treated i.p. at -1 and $3 \mathrm{~h}$ after a withdrawal with the drug (citalopram, $20 \mathrm{mg} / \mathrm{kg} / \mathrm{mL}$ or tianeptine, $20 \mathrm{mg} / \mathrm{kg} / \mathrm{mL}$ ) or an equal volume of vehicle $(2 \mathrm{~mL} / \mathrm{kg})$. The animals were killed (by decapitation) $4 \mathrm{~h}$ after the last injection, i.e. $7 \mathrm{~h}$ after withdrawal. The behavioral activity of the animals for both control and drug treated was monitored (Oretti et al., 1996). Rats were killed by decapitation and their livers were perfused in situ with ice-cold $0.9 \%$ saline and were rapidly removed and frozen in liquid nitrogen until analysis.

\section{Microdissection of brain}

A fresh brain was dipped in ice-cold saline and placed with its dorsal side up in the molded cavity of a brain slicer (Henry and Yashpal, 1984). A fine fishing line wire was inserted into the slots of the slicer to give slices of $1 \mathrm{~mm}$ thickness. The slices were transferred to a Petri dish kept on ice, moistened with ice-cold $0.9 \% \mathrm{NaC} 1$ and the desired brain regions identified with the aid of a stereotaxic atlas (Paxinos and Watson, 1982). Olfactory nucleus material was discarded from the slice containing cortex. Hippocampal material (CA1-4 fields + subiculum + dentate gyrus) was dissected out with a sharp scalpel and the hypothalamus and amygdala regions were obtained by taking punches of $2 \mathrm{~mm}$ diameter from slices.

\section{Brain neurochemical analysis}

Brain tissues were weighed, homogenized and deproteinized in volumes of $0.1 \mathrm{M}$ Perchloric acid (1g in $4 \mathrm{~mL} 0.1 \mathrm{M}$ perchloric acid). The homogenates were sonicated at $0-4^{\circ} \mathrm{C}$ at a medium setting for two $15 \mathrm{~s}$ periods using a sonicator. After adding $0.5 \mathrm{~mL}$ of $4 \mathrm{M}$ perchloric acid and mixing the samples were spun at $10,000 \mathrm{~g}$ for $10 \mathrm{~min}$ at $4^{\circ} \mathrm{C}$ and a portion of the supernatant was taken and stored at $-70^{\circ} \mathrm{C}$ for analysis.

The analytical measurements were performed by high-performance liquid chromatography with a fluorescent detector. A reverse phase chromatography was used for the analysis of TRP, 5-HT and its metabolite 5hydroxyindolacetic acid (5-HIAA). The ratio of 5HIAA/5-HT was used as an index of 5-HT turnover. For mobile phase $0.01 \mathrm{M}$ sodium acetate was made and $\mathrm{pH}$ was adjusted up to 4.5 with glacial acetic acid and finally, the volume was made up to $1 \mathrm{~L}$ with water. $15 \%$ methanol was added to filtered mobile phase and was passed through the ODS separation column $(25 \mathrm{~cm}$ in length $4.6 \mathrm{~mm}$ in diameter) at a constant flow rate $(2 \mathrm{~mL} / \mathrm{min})$ with an operating pressure of 2000-3000 psi, using a 200 series pump. Fluorescence detection was performed on Shimadzu VT 03 detector at an operating potential of $0.8 \mathrm{~V}$. The fluorimetric detector was used with 254-nm excitation and 360 $\mathrm{nm}$ excitation (Anderson et al., 1981).

\section{Drugs and chemicals}

The drug citalopram $(20 \mathrm{mg} / \mathrm{kg} / \mathrm{mL})$ as $(\mathrm{HBr}$; Lundbeck Pakistan private limited) and tianeptine (20mg/kg/mL), (Servier, Pakistan) were dissolved in saline. All other chemicals used were from SigmaAldrich, St Louis MO USA. Drugs were freshly prepared.

\section{Statistical analysis}

Data was analyzed by one-way ANOVA followed by Dunnet's test and where appropriate using student's t-test. The $\mathrm{P}$ value of $<0.05$ was considered to be statistically significant.

\section{RESULTS AND DISCUSSION}

Effects of alcohol withdrawal on brain regional tryptophan metabolic changes

Figure 1-4 shows the effects of alcohol withdrawal on brain regional tryptophan metabolism. There was shows significant decreases in tryptophan concentration, 5-HT and 5HIAA concentrations in hypothalamus, amygdala, hippocampus regions in alcohol withdrawal rats. These results are in agreement with the findings reported earlier (Ara and Bano, 2015) with the experimental evidences that the abnormal 5-HT functions in alcoholism is associated with a low number of 5-HT transporters binding sites in the living and postmortem brains of alcoholics (Heinz et al., 2000; Kranzler et al., 2002). Generally alcohol elevates serotonin in brain regions (Ding et al., 2012) by increasing the activity of serotonin receptors 5HT3, 5HT1A, 5HT1B, and serotonin transporters therefore low serotonin turnover accounts for the negative mood states, aggressive behavior, feeling of insecure and threat that leads to the development of anxiety behavior (Sari et al., 2011; Virkunen et al., 1994; Johnson, 2004). Therefore an AW-induced reduction in serotonin turnover in all the regions in the present results confirm the hypothesis consistent with the development of agitation, tremors, stereotype behavior, WDS and audiogenic seizures (Overstreet et al., 2004) (Table I). 

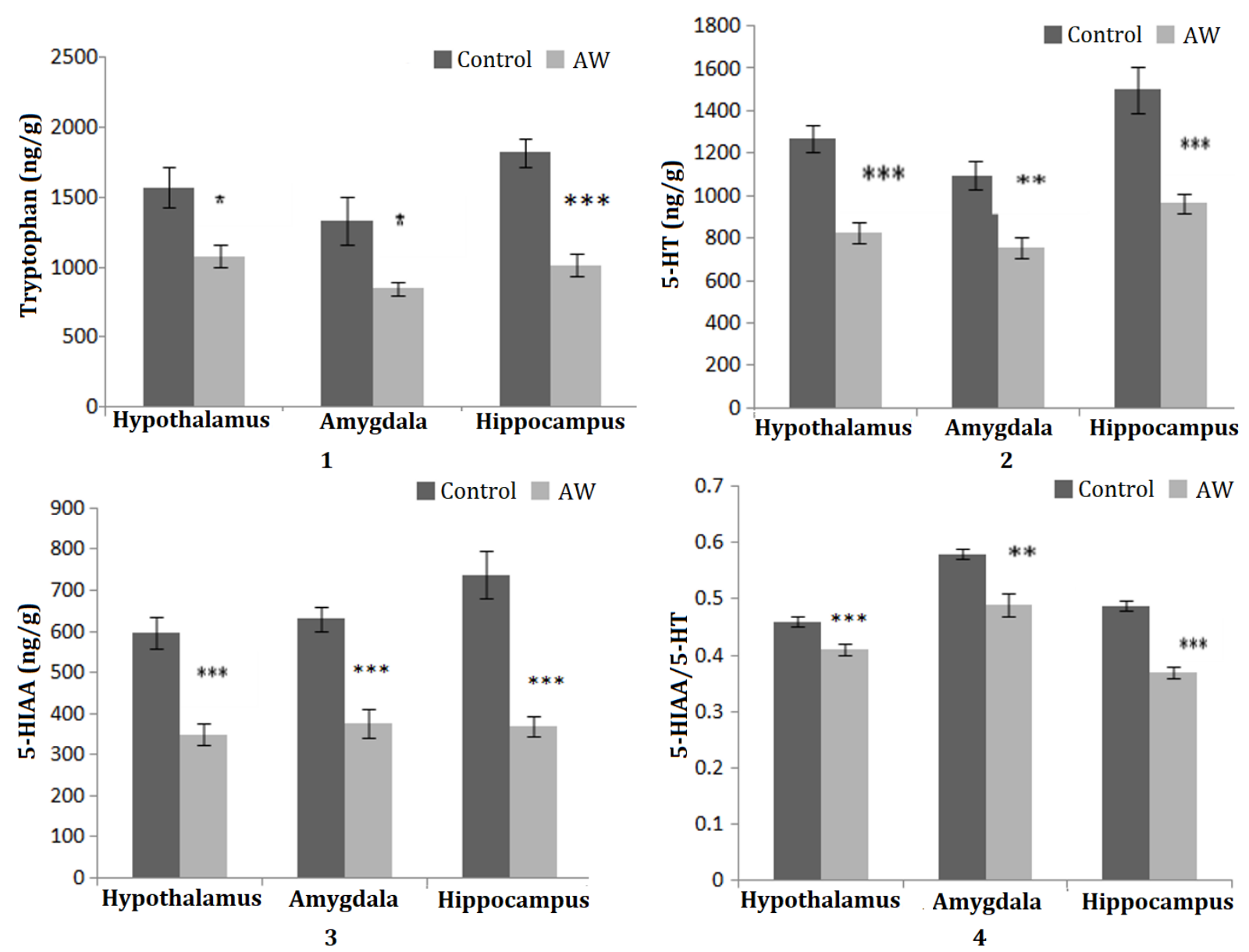

Figure 1-4. Effect of alcohol withdrawal on brain regional (1) tryptophan (2)5-HT (3) 5hIAA and (4) 5HIAA/5HT concentration expereimental details are given in material and methods section. All values are means \pm S.E.M for each group of eight rats. The values obtained in control rats were compared statistically by students $t$-test with those obtained in group of rats withdraw from alcohol. The significance of difference is indicated as follows ${ }^{*} \mathrm{P}<0.05,{ }^{* *} \mathrm{P}<0.01,{ }^{* * * *} \mathrm{P}<0.001$.

Effects of citalopram and tianeptine on brain regional tryptophan metabolic changes and on the blockade of Alcohol Withdrawal signs in AW rats

Citalopram and tianeptine effectively prevented alcohol withdrawal-induced agitation and autogenic seizures when compared to vehicle-treated alcohol-withdrawn rats (Table I). However, tianeptine was found to be more effective in preventing tremors, stereotype behavior and wet dog shakes. Earlier investigators have reported that tianeptine and fluoxetine had similar affinity to block alcohol withdrawal symptoms; however, escitalopram had lesser affinity comparatively. Anxiety-like behavior following chronic ethanol dependence has been characterized as a set of withdrawal symptoms and tianeptine has been proposed to possess anxiolytic property (Uzbay, 2008; File et al., 1993; McEwen et al., 2010).

The results of the present study are in agreement with our previous findings that the tianeptine $(10 \mathrm{mg} / \mathrm{kg})$ and the citalopram $(20 \mathrm{mg} / \mathrm{kg})$ increased brain tryptophan concentration (Bano et al., 2010; Ara and Bano, 2012).

Results analyzed by one way ANOVA (Table II) shows significant effects of citalopram and tianeptine on tryptophan levels in hypothalamus $(\mathrm{F}=11.86 ; \mathrm{P}<0.01)$, in amygdala $(\mathrm{F}=10.68 ; \mathrm{P}<0.01)$ and in hippocampus $(\mathrm{F}=12.18$; $\mathrm{P}<0.01)$. Dunne's test shows the rise in tryptophan $(p<0.01)$ by the citalopram in all regions, while, tianeptine shows insignificant effects only in the hypothalamic region. 
Table I. Prevention of alcohol-withdrawal seizures by citalopram and tianeptine

\begin{tabular}{|c|c|c|c|c|c|}
\hline \multirow{2}{*}{ Treatment } & \multicolumn{5}{|c|}{ Alcohol withdrawal } \\
\hline & Agitation & Tremors & Stereotyped & WDS & AS \\
\hline AW+Saline & 0 & 0 & 0 & 0 & 0 \\
\hline AW+Citalopram & ftt & It & It & fi & ftt \\
\hline AW+Tianeptine & flt & flt & flt & it & tft \\
\hline
\end{tabular}

0: innefectife; t:statistically mild significant attenuation; - ft: statistically moderatt inhibitory effectd; flt : high inhibitory effect; WDS=Wet Dog Shake; AS: Auduigenic seizures.

Table II. effect of tianeptine and citalopram on brain regional tryptophan metabolic changes in AW rats. Statistical analysis was performed using one way ANOVA followed by Dunnett's test.

\begin{tabular}{|c|c|c|c|c|}
\hline $\begin{array}{c}\text { Concentration in } \\
\text { (ng/gm wet wt of } \\
\text { tissue) }\end{array}$ & $\begin{array}{c}\text { Alcohol } \\
\text { Withdrawal }\end{array}$ & $\begin{array}{c}\text { Alcohol } \\
\text { Withdrawal + } \\
\text { Tianeptine } \\
\end{array}$ & $\begin{array}{c}\text { Alcohol } \\
\text { Withdrawal + } \\
\text { Citalopram } \\
\end{array}$ & $\begin{array}{c}\text { One Way ANOVA } \\
\text { Df } 1.15\end{array}$ \\
\hline \multicolumn{5}{|l|}{ HYPOTHALAMUS } \\
\hline TRP & $1079.6 \pm 76.0$ & $1114.6 \pm 108.2$ & $1715 \pm 121.7 \mathrm{tt}$ & $F=11.86(P<0.01)$ \\
\hline 5-HT & $829 V 49.3$ & $754.6 \pm 43.0$ & $1341 \pm 122 \mathrm{ft}$ & $F=22.06(P<0.01)$ \\
\hline 5-HIIA & $349.1 \pm 25.1$ & $500.6 \pm 43.1 *$ & $504.5 \pm 47.7 \mathbf{t}$ & $\mathrm{F}=4.92(\mathrm{P}<0.05)$ \\
\hline 5-HIIA/5-HT & & $0.66 \pm 0.03^{* *}$ & $0.37 \pm 0.02$ & $\mathrm{~F}=34.19(\mathrm{P}<0.01)$ \\
\hline \multicolumn{5}{|l|}{ AMYGDALA } \\
\hline TRP & $848 \pm 46.5$ & $1421.8 \pm 101^{* *}$ & $1306.5 \pm 116.2 \mathrm{tt}$ & $F=10.68(P<0.01)$ \\
\hline 5-HT & $755.3 \pm 50.5$ & $834 \pm 39.7$ & $1021 \pm 57.6 \mathrm{ft}$ & $\mathrm{F}=7.09(\mathrm{P}<0.05)$ \\
\hline 5-HIIA & $375.1 \pm 35.3$ & $547.1 \pm 45.9^{*}$ & $423.6 \pm 45.6$ & $\mathrm{~F}=4.33(\mathrm{P}<0.05)$ \\
\hline 5-HIIA/5-HT & $0.49 \pm 0.02$ & $0.64 \pm 0.02^{* *}$ & $0.41 \pm 0.03$ & $\mathrm{~F}=16.73(\mathrm{P}<0.01)$ \\
\hline \multicolumn{5}{|l|}{ HIPPOCAMPUS } \\
\hline TRP & $1015 \pm$ & $1631 \pm 152.3^{* * *}$ & $1808 \pm 113.6 \mathrm{ft}$ & $\mathrm{F}=12.18(\mathrm{P}<0.01)$ \\
\hline 5-HT & $964 \pm$ & $1038.6 \pm 103.5$ & $1428 \pm 111.7$ tf & $\mathrm{F}=7.94(\mathrm{P}<0.01)$ \\
\hline 5-HIIA & $367 \pm$ & $711.1 \pm 77.4^{* *}$ & $701.5 \pm 59.0 \mathrm{ft}$ & $\mathrm{F}=11.3(\mathrm{P}<0.05)$ \\
\hline 5-HIIA/5-HT & $0.37 \pm$ & $0.68 \pm 0.01^{* *}$ & $0.48 \pm 0.01 \mathrm{t}$ & $\mathrm{F}=25.8(\mathrm{P}<0.01)$ \\
\hline
\end{tabular}

Serotonin deficiency is caused by a decreased availability of its precursor tryptophan to the brain. This decrease is caused by accelerated Trp degradation, most likely induced by enhancement of the hepatic enzyme tryptophan 2,3-dioxygenase (TDO) by glucocorticoids and/or catecholamines. Liver TDO appears to be a target of many antidepressants; Enhancing Trp availability to the brain is thus the key to normalization of serotonin synthesis and could form the basis for future antidepressant drug development (Badawy, 2013; Bano et al., 2010; Bano and Sherkheli, 2003). Alternatively tryptophan depletion exerts serotonergic dysfunction related to depression, anxiety, and cognitive impairment (Badawy, 2002; 2013; Richard et al., 2009)

Increases in tryptophan levels in the hypothalamus were not significant, that may pinpoint the dose-dependent effects of tianeptine.
Since, hypothalamus predominantly regulates the visceromotor functions by adjusting the balance between sympathetic and parasympathetic outputs to the autonomic nervous system (Flugge, 1999; Fuchs and Flugge, 2003) therefore neuroanatomical factors may add to the development of tolerance in specific brain areas in alcohol dependence. Further, serotonergic drugs presumably downregulate and reverse the activity of receptors and transporters that are up-regulated in the presence of alcohol (Johnson, 2004; Sari et al., 2011).

Effects of drugs on brain regional tryptophan metabolism (Table II). Data analyzed by one way ANOVA shows significant effects on 5-HT in hypothalamus $(\mathrm{F}=22.06 ; \quad \mathrm{P}<0.01), \quad$ amygdala $(\mathrm{F}=7.09 ; \mathrm{P}<0.05)$ and in hippocampus ( $\mathrm{F}=7.94$; $\mathrm{P}<0.01)$. Dunnett's test shows insignificant changes in all the three regions by tianeptine while 
citalopram shows a significant increase $(\mathrm{p}<0.001)$. Citalopram, a serotonergic re-uptake inhibitor, act by enhancing synaptic 5-HT concentrations by increasing the availability of tryptophan as reported earlier (Ara and Bano, 2012). However, insignificant change in 5-HT by tianeptine may suggests its unique pharmacological profile as indirect acting drugs. Microdialysis study reported that the acute and chronic treatment of tianeptine did not alter extracellular serotonin concentration in rat frontal cortex and raphe nuclei (Malagie et al., 2000). Similarly, Fattaccini et al., (1990) reported no change in 5-HT in brain tissue with the increased concentration of 5-HIAA following $1 \mathrm{~h}$ of acute tianeptine $(10 \mathrm{mg} / \mathrm{kg})$ administration. However, chronic treatment increased serotonin uptake at the dose $20 \mathrm{mg} / \mathrm{kg}$, (i.p) in hippocampus and cortex (Mennini and Garattini, 1991).

Studies conducted earlier have reported that chronic alcohol consumption may lead to reduced binding potential of the serotonergic drugs for serotonin transporters. (Mantere et al., 2002; Storvik et al., 2008) however, subsequent use of serotonergic drugs may overcome these effects via increasing binding affinity (Ketcherside et al., 2013; Garbutt, 1999). Immunohistochemistry studies by Jang et al., (2002) showed reduction in the expression of the tryptophan hydroxylase (the ratelimiting enzyme in serotonin synthesis) upon alcohol exposure in rats. According to another study, 4-week administration of tianeptine and fluoxetine enhanced the density of 5-HT and serotonin transporter-immunoreactive in the neocortical layer IV and certain forebrain limbic brain areas with insignificant effects on tryptophan hydroxylase 2 and serotonin transporter at mRNA level (Zhou et al., 2006). In view of the present findings, tianeptine appears to exert its effects indirectly on serotonergic neurons by causing inhibition in the release of neurotransmitter from the vesicles, Therefore, tianeptine might play significant role in attenuating the alcohol-induced aggression and withdrawal symptoms by altering serotonergic neurotransmission.

Our data (Table II) shows significant effects of citalopram and tianeptine on serotonin turnover (5-HIAA/5-HT) in hypothalamus ( $\mathrm{F}=34.19 ; \mathrm{P}<0.01)$, amygdala $(\mathrm{F}=16.73 ; \mathrm{P}<0.01)$ and in hippocampus $(\mathrm{F}=25.8 ; \mathrm{P}<0.01)$, These significant effects show the rise in 5 -HT turnover by tianeptine in all the three regions $(\mathrm{P}<0.01)$, with the significant increase in hippocampus only $(\mathrm{p}<0.05)$ by citalopram. Since alcohol mimics serotonergic responses and withdrawal indices low serotonin turnover rate, therefore, increased 5-HT turnover rate by these antidepressants, more prominently by the tianeptine commensurate with the preventive effects on alcohol withdrawal signs. The results of the present findings are in agreement with previous studies (Uzbay, 2008). File and coworkers (1993) have found tianeptine reduced AW related anxious behavior and hypoactivity in social interaction when administered to rats (File et al., 1993), while, the anxiogenic profile was observed when administered chronically in mice for 21 days (Cutler et al., 1997; Rodgers et al., 1997). In contrast, clinical findings suggest that citalopram appears to reduce the drive to alcohol consumption only moderately to some alcoholics and does not contribute to reducing pathogenesis effectively (Naranjo et al., 2000; 1992; Martijena et al., 2005). However, other SSRIs such as fluoxetine has shown to reduce alcohol intake and craving compared to baseline only at higher doses (60mg) (Naranjo et al., 1990; 1994). It has been reported that long-term tianeptine treatment had some beneficial effects to recover depression and anxiety related symptoms in patients with alcoholism (Malka et al., 1992). Therefore, the adaptive changes in the 5-HT system may play a crucial role in the therapeutic effect of antidepressant treatments (Warner-Schmidt et al., 2006).

\section{CONCLUSION}

The anxiolytic characteristics of citalopram and tianeptine both provide novel findings as a useful treatment for the prevention of alcohol withdrawal behavioral syndrome. Unlike citalopram, the mechanism of action of tianeptine remain speculative for its interaction and binding affinity with intraneuronal and membrane transport protein and channels. While the notion that citalopram improves serotonin dysfunction may still be a matter of debate as higher doses in clinical trials can provide better therapeutic options and understanding the neurobiological basis of AWS. There is no doubt that a comprehensive approach to the mechanism of serotonin transporters is paving a road to better pharmacological management of alcohol withdrawal syndrome.

\section{ACKNOWLEDGMENT}

We thank Grant support from Higher Education Commission Pakistan for financial support. 


\section{REFERENCES}

Anderson GM., Young JG. Batter DK, Young SN., Cohen DJ. and Shaywitz BA., 1981. Determination of indoles and catechols in rat brain and pineal using liquid chromatography with fluorometric and amperometric detection. J Chromatogr 223(2): 315-20.

Ara I. and Bano S., 2012. Citalopram decreases tryptophan 2, 3 dioxygenase activity and brain 5-HT turnover in swim stressed rats Pharmacol Rep 64(3):558-66.

Ara I. and Bano S., 2015. Serotonergic activity and hypothalamic-pituitary-adrenal axis response in alcohol administered and subsequently withdrawn rats Pak J Pharm Sci. 28(4):1259-65.

Badawy AA. and Aliyu SU., 1984. Antagonism of acute alcohol intoxication by naloxone Alcohol Alcohol.19(3):199-201.

Badawy AA., 2002. Tryptophan metabolism in alcoholism. Nutr Res Rev. 15(1):123-52. doi: 10.1079/NRR200133.

Badawy AA., 2013. Tryptophan: the key to boosting brain serotonin synthesis in depressive illness. J Psychopharmacol. 27(10):878-93.

Banerjee N., 2014.Neurotransmitters in alcoholism: A review of neurobiological and genetic studies. Ind J Hum Genet 20 (1): 20-31.

Bano S., Gitay M., Ara I. and Badawy A., 2010 Acute effects of serotonergic antidepressants on tryptophan metabolism and corticosterone levels in rats. PakJ Pharm Sci 23: 266-72.

Bano S. and Sherkheli MA., 2003 Inhibition of tryptophan - pyrrolase activity and elevation of brain tryptophan concentration by fluoxetine in rats $J$ Coll Physicians Surg Pak. 13(1):5-10.

Bano S., Oretti RG., Morgan CJ., Badawy AA-B., Buckland PR. and McGuffin P., 1996. Effects of chronic administration and subsequent withdrawal of ethanol-containing liquid diet on rat liver tryptophan pyrrolase and tryptophan metabolism. Alcohol and Alcoholism 31: 205-215.

Brink CB., Harvey BH. and Brand L. 2006. Tianeptine: a novel atypical antidepressant that may provide new insights into the biomolecular basis of depression. Recent Pat CNS Drug Discov.1:29-41.

Calabozo B., Molina V., and Uribe F., 2016. Tianeptine: Why has it not been classified as a narcotic in Spain? Rev Psiquiatr Salud Ment (Barc.). 9:176---177.
Cutler MG., Rodgers RJ. and Jackson JE., 1997. Behavioural effects in mice of subchronic buspirone, ondansetron and tianeptine. I. Social interactions. Pharmacol Biochem Behav. 56(2):287-93.

Ding ZM., Oster SM., Hauser SR., Toalston JE., Bell RL., et al., 2012. Synergistic selfadministration of ethanol and cocaine directly into the posterior ventral tegmental area: involvement of serotonin-3 receptors. $J$ Pharmacol Exp Ther 340: 202-209.

Fattaccini CM., Bolanos-Jimenez F., Gozlan H. and Hamon M., 1990.Tianeptine stimulates uptake of 5-hydroxytryptamine in vivo in the rat brain. Neuropharmacology 29: 1-8.

Favre JD., Guelfi-Sozzi C., Delalleau B. and Lôo H. 1997., Tianeptine and alcohol dependence. Eur Neuropsychopharmacol. 3:S347-51.

File SE., Andrews N. and al_Farhan M., 1993. Anxiogenic responses of rats on withdrawal from chronic ethanol treatment effects of tianeptine. Alcohol Alcohol 28 (3): 281-6.

Flügge G., 1999. Effects of cortisol on brain alpha2adrenoceptors: potential role in stress. 1999 Neurosci Biobehav Rev.23(7):949-56.

Fuchs E., Flügge G., 2003. Chronic social stress: effects on limbic brain structures. Physiol Behav 79, 417-27.

Garbutt JC., West SL., Carey TS., Lohr KN. and Crews FT., 1999; Pharmacological treatment of alcohol dependence: a review of the evidence. JAMA. 281:1318-25.

Harper C., Matsumoto I., Pfefferbaum A., Adalsteinsson E., Sullivan EV., et al., 2005.The Pathophysiology of 'Brain Shrinkage' in Alcoholics - Structural and Molecular Changes and Clinical Implications. Alcohol Clin Exp Res, 29 (6): 1106-1115.

Heinz A., Jones DW., Mazzanti C., Goldman D., Ragan P., Hommer D. et al., 2000. Serotonin transporter genotype interacts with in vivo protein expression and alcohol neurotoxicity. Biol Psychiatry 47:643- 649.

Henry JL. and Yashpal K., 1984. Rat brain slicer. A simple device for rapidly obtaining serial slabs of fresh brain. Brain Res Bull 13(1):1957.

Hindmarch I., 2001 Expanding the horizons of depression: beyond the monoamine hypothesis. Hum Psychopharmacol. 16(3):203-218.

Hunter BE., Riley JN., and Walker DW., 1975. Ethanol dependence in the rat: a parametric 
analysis Pharmacol Biochem Behav 3 (4): 619-29.

Jang MH., Shin MC., Lee TH., Kim YP., Jung SB. et al., 2002. Alcohol and nicotine administration inhibits serotonin synthesis and tryptophan hydroxylase expression in dorsal and median raphe of young rats. Neuroscie. Lett. 329(2):141-4.

Johnson BA., 2004. Role of the serotonergic system in the neurobiology of alcoholism: implications for treatment. CNS Drugs 18(15):1105-18.

Ketcherside A., Matthews I. and Filbey F., 2013 The Serotonin Link between Alcohol Use and Affective Disorders Journal of addiction and prevention.1(2);1-5

Koob GF. 2000. Neurobiology of addiction. Toward the development of new therapies. Ann $N Y$ Acad Sci 909:170-85.

Kranzler H., Lappalainen J., Nellissery M. and Gelernter J., 2002. Association study of alcoholism subtypes with a functional promoter polymorphism in the serotonin transporter protein gene. Alcohol Clin Exp Res 26(9):1330-5.

Liu W., Shu XJ., Chen FY., Zhu C., Sun XH. et al., 2011. Tianeptine reverses stress-induced asymmetrical hippocampal volume and $\mathrm{N}$ acetylaspartate loss in rats: an in vivo study .Psychiatry Res; 194 (3).385-392.

Majchrowicz E., 1975. Induction of physical dependence upon ethanol and the associated behavioral changes in rats. Psychopharmacologia 17, 43(3):245-54.

Malagié I., Deslandes A., and Gardier AM., 2000. Effects of acute and chronic tianeptine administration on serotonin outflow in rats: comparison with paroxetine by using in vivo microdialysis. Eur J Pharmacol 403(1-2):5565.

Malka R., Loo H., Ganry H. et al., 1992. Long-term administration of tianeptine in depressed patients after alcohol withdrawal. British Journal of Psychiatry 160 (Suppl. 15), 66-71.

Mantere T., Tupala E., Hall H., Sarkioja T., Rasanen P., Bergstrom K. et al., Serotonin transporter distribution and density in the cerebral cortex of alcoholic and nonalcoholic comparison subjects: a whole-hemisphere autoradiography study. Am J Psychiatry. 2002; 159:599-606

Martijena ID., Bustos SG., Bertotto ME. and Molina VA., 2005. Antidepressants attenuate both the enhanced ethanol intake and ethanol- induced anxiolytic effects in diazepam withdrawal rats. Eur Neuropsychopharmacol. Jan 15(1):119-30.

McEwen BS., Chattarji S., Diamond DM., Jay TM., Reagan LP., et al., 2010. The neurobiological properties of Tianeptine (Stablon): from monoamine hypothesis to glutamatergic modulation. Mol Psychiatry. 15(3):237-49.

Mennini T., and Garratini S., 1991. Neurobiology of Tianeptine. A new pharmaceutic agent Presse Med 20(37):1823-7.

Naranjo CA., Kadlec KE., Sanhueza P., WoodleyRemus D., and Sellers EM., 1990. Fluoxetine differentially alters alcohol intake and other consummatory behaviors in problem drinkers. Clin Pharmacol Ther. 47(4):490498.

Naranjo CA., Poulos CX., Bremner KE. and Lanctot KL., 1994. Fluoxetine attenuates alcohol intake and desire to drink. Int Clin Psychopharmacol.;9(3):163-172.

Naranjo CA., Knoke DM. and Bremner KE., 2000. Variations in response to citalopram in men and women with alcohol dependence. $J$ Psychiatry Neurosci. 25(3):269-75.

Naranjo CA., Poulos CX., Bremner KE. and Lanctôt KL., 1992. Citalopram decreases desirability, liking, and consumption of alcohol in alcoholdependent drinkers Clin Pharmacol Ther:;51(6):729-39.

Oluyomi AO., Datla KP. and Curzon G., 1997. Effects of the (+) and (-) enantiomers of the antidepressant drug tianeptine on 5-HT induced behaviour. Neuropharmacology 36: 383-7.

Oretti R., Bano S., Morgan CJ., Badawy AA., Bonner A., Buckland P. and McGuffin P., 1996. Prevention by cyclohexamide of the audiogenic seizures and tryptophan metabolic disturbances of ethanol withdrawal in rats. Alcohol Alcohol 31(3): 243-7.

Oscar-Berman M. and Marinkvoic K., 2003. Alcoholism and the brain. Alcohol Research and health. 27(2): 125-33

Oscar-Berman M., 2000. Neuropsychological vulnerabilities in chronic alcoholism. In: Noronha, A.; Eckardt, M.J.; and Warren, K.. Review of NIAAA's Neuroscience and Behavioral Research Portfolio. 34:437-471.

Overstreet DH., Knapp DJ., and Breese GR., 2004 Similar anxiety-like responses in male and female rats exposed to repeated withdrawals 
from ethanol. Pharmacol Biochem Behav. 78(3):459-64.

Paxinos G and Watson C., 1982. The Rat brain in stereotaxic coordinates

Pihl RO. and LeMarquand D.,1998. Serotonin and aggression and the alcohol- aggression relationship. Alcohol Alcohol.33 (1): 55-65

Richard DM., Dawes MA. and Mathias CW, Acheson A, Hill-Kapturczak N, Dougherty DM.L., 2009. Tryptophan basic metabolic functions.Behavioural Research and Therapeutic indications Int J Tryptophan Res. 23;2:45-60.

Rodgers RJ., Cutler MG. and Jackson JE., 1997. Behavioural effects in mice of subchronic buspirone, ondansetron and tianeptine. II. The elevated plus-maze Pharmacol Biochem Behav. 56(2):295-303.

Rosennloom MJ., and Pfefferbaum A., 2008. Magnetic resonance imaging of the living brain: Evidence for brain degeneration among alcoholics and recovery with abstinence. Alcohol Research and Health 31:362-376.

Sanchez C., 2006. The pharmacology of citalopram enantiomers: the antagonism by Rcitalopram on the effect of S-citalopram. Basic Clin Pharmacol Toxicol. 99:91-5.

Sari Y., Johnson VR. and Weedman JM., 2011. Role of the serotonergic system in Alcohol dependence: From animal models to Clinics. Prog Mol. Biol Transl Sci 98: 401-443.

Sarnyai Z., Shaham Y. and Heinrichs SC., 2001 The role of corticotropin-releasing factor in drug addiction. Pharmacol Rev. 53(2): 209-43.

Storvik M., Haukijarvi T., Tupala E. and Tiihonen J., 2008. Correlation between the SERT binding densities in hypothalamus and amygdala in Cloninger type 1 and 2 alcoholics. Alcohol Alcohol. 43:25-30.
Thompson WL., 1978. Management of alcohol withdrawal syndromes. Advances in Internal Medicine 138: 278-283.

Uzbay IT., 2008 Serotonergic anti-depressants and ethanol withdrawal syndrome: a review. Alcohol Alcohol 43(1): 15-24.

Uzbay IT. and Kayaalp SO., 1995. A modified liquid diet of chronic ethanol administration: Validation by ethanol withdrawal syndrome in rats. Pharmacological Research 31: 37-42.

Vadachkoria D., Gabunia L., Gambashidze K., Pkhaladze N. and Kuridze, 2009. N Addictive potential of Tianeptine - the threatening reality. Georgian Med News. 174:92-4.

Virkkunen M., Kallio E., Rawlings R., Tokola R., Poland RE. et al., 1994. Personality profile and state aggressiveness in Finnish alcoholic, violent offenders, fire setters, and healthy volunteers. Arch Gen Psychiatr. 51(1): 28-33.

Warner-Schmidt JL. and Duman RS., 2006. Hippocampal neurogenesis: Opposing effects of stress and antidepressant treatment. Hippocampus 16 (3): 239-49.

Zahr NM., Pfefferbaum A.,2017. Alcohol's effects on the brain: Neuroimaging results in human and animal models. Alcohol Res. 38(2):183206.

Zhong H., Hansen KB., Boyle NJ., Han K., Muske G., et al., 2009. An allosteric binding site at the human serotonin transporter mediates the inhibition of escitalopram by R-citalopram: kinetic binding studies with the ALI/VFLSI/TT mutant. Neurosci Lett.

Zhou L., Huang KX., Kecojevic A., Welsh AM. and Koliatsos VE., 2006. Evidence that serotonin reuptake modulators increase the density of serotonin innervation in the forebrain. $J$ Neurochem. 96. (2):396-406. Epub 2005 